\title{
Psychotropic Medication Usage for Psychiatric Emergencies in a Tertiary Health Care Centre in Nigeria
}

\author{
Aina $\mathrm{IO}^{1}$ and Israel-Aina $\mathrm{YT}^{2}$
}

\begin{abstract}
Background: This study documented the usage of psychotropics in patients presenting with psychiatric emergencies. The usage of psychotropic medications has to do with the prescription pattern of the clinicians in any setting.
\end{abstract}

Materials \& Methods: A retrospective study carried out at the Accident and Emergency Unit of University of Benin Teaching Hospital, Benin City, between 2008 and 2018. Case notes of patients who presented with psychiatric emergencies were retrieved, data extracted and analyzed.

Results: A total of one hundred and fourteen patients were studied over a 10 year period. Most patients (82.5\%) were diagnosed with psychotic disorders. Antipsychotics accounted for $67.5 \%$ of all prescriptions. Chlorpromazine was the most commonly prescribed oral psychotropic (22.8\%). Mood stabilizers were $12.3 \%$ while antidepressants were $12.3 \%$ of all prescriptions.

Parenteral psychotropics were used more as combination (60.5\%) than as single parenteral medication (14.0\%). Commonest combination of parenteral psychotropic was Chlorpromazine and Diazepam. Long-acting medications commonly used were Fluphenazine Decanoate (20.8\%) and Flupenthixol Decanoate (17.4\%).

Conclusion: Oral antipsychotics were more prescribed with Chlorpromazine and Haloperidol as commonest. Amitriptylline was the commonest antidepressant prescribed while Chlorpromazine and Diazepam were the commonest parenteral psychotropic used. Fluphenazine Decanoate and Flupenthixol Decanoate were the commonest long-acting parenteral medications prescribed

Keywords: Psychotropics, prescription pattern, psychiatric emergency, Nigeria.

\author{
*Corresponding Author \\ Dr. I.O. Aina \\ http://orcid.org/0000-0003-4652-2173 \\ E-mail: israelaina@yahoo.com
}

${ }^{1}$ Department of Mental Health, University of Benin Teaching Hospital, Benin City, Edo State, Nigeria. ${ }^{2}$ Department of Child Health, University of Benin Teaching Hospital, Benin City, Edo State, Nigeria. 


\title{
L'utilisation de médicaments psychotropes pour les urgences psychiatriques dans un tertiaire centre de soins de santé au Nigéria
}

\author{
Aina $\mathrm{IO}^{1}$ and Israel-Aina $\mathrm{YT}^{2}$
}

\section{Résumé}

Contexte général de l'étude : Les médicaments psychotropes sont des médicaments utilisés pour traiter les troubles mentaux. L'utilisation de médicaments est liée au modèle de prescription des cliniciens dans n'importe quel contexte. Ainsi, cette étude a documenté l'utilisation des psychotropes chez les patients présentant des urgences psychiatriques.

Matériaux et méthodes de l'étude : Étude rétrospective qui a été effectuée à l'unité des accidents et d'urgence de l'Université du Bénin Centre hospitalier universitaire, Ville Bénin. Les notes de cas des patients qui ont présenté des urgences psychiatriques ont été récupérées, les données extraites et analysées.

Résultats de l'étude : Cent quatorze patients ont été étudiés. La plupart des patients $(82,5 \%)$ ont reçu un diagnostic de troubles psychotiques. Les antipsychotiques représentaient $67,5 \%$ de toutes les ordonnances. La chlorpromazine était le psychotrope oral le plus couramment prescrit $(22,8 \%)$. Les stabilisateurs de l'humeur représentaient $12,3 \%$ tandis que les antidépresseurs représentaient $12,3 \%$ de toutes les ordonnances. L'antidépresseur le plus couramment prescrit était l'amitriptylline. Les psychotropes parentéraux ont été plus utilisés en association (60,5\%) qu'en médicament monoparental (14,0\%). L'association la plus courante de psychotropes parentéraux était la chlorpromazine et le diazépam dans $55,7 \%$ des cas. Les médicaments à action prolongée couramment utilisés étaient le décanoate de fluphénazine $(20,8 \%)$ et le décanoate de flupenthixol $(17,4 \%)$.

Conclusion: Les antipsychotiques oraux étaient plus prescrits, la chlorpromazine et l'halopéridol étant les médicaments les plus couramment utilisés. L'amitriptylline est l'antidépresseur le plus courant, tandis que la chlorpromazine et le diazépam étaient les psychotropes parentéraux les plus couramment utilisés. Le décanoate de fluphénazine et le décanoate de flupenthixol étaient les médicaments parentéraux à action prolongée les plus couramment prescrits.

Mots-clés : Psychotropes, utilisation, e psychiatrique Mergency, Nigéria

\section{*Corresponding Author}

Dr. I.O. Aina

http://orcid.org/0000-0003-4652-2173

E-mail: israelaina@yahoo.com

${ }^{1}$ Department of Mental Health, University of Benin Teaching Hospital, Benin City, Edo State, Nigeria. ${ }^{2}$ Department of Child Health, University of Benin Teaching Hospital, Benin City, Edo State, Nigeria. 


\section{INTRODUCTION}

Psychotropic medications are medicinal drugs used for the treatment of mental disorders. These medications are used to correct abnormalities in the mind, emotions and behaviour of individuals. They are licensed psychoactive drug taken to exert an effect on the chemical makeup of the brain and nervous system. ${ }^{1}$ Thus, these medications which have revolutionized the care of the mentally-ill are usually prescribed in psychiatric settings ${ }^{2}$. They are typically made of synthetic chemical compounds. ${ }^{3}$ Psychotropic medications are otherwise called psychotropics, psychodynamic medication or psychiatric medications. ${ }^{4,5}$ Psychotropics fall into different categories such as antipsychotics, antidepressants, anxiolytics, mood stabilizers etc. ${ }^{6}$ The need for an urgent intervention is the reason why patients with mental disorders present to an emergency psychiatric unit and pharmacological restraints of these patients is a common feature in psychiatric practice in the emergency setting. Determination of the medication to be used in any setting ought to be based on evidence, clinical practice guidelines and the Essential Medicine List (EML) where applicable.

To guide the development of clinical guidelines therefore, it is imperative to understand the prescription pattern in a setting as well as have an indepth knowledge of the factors affecting drug use pattern. Again, prescription use pattern also serve as a measure of the adherence to the standard treatment guidelines and the EML in the facility or locale. This ensures that medicines are used rationally and ensures availability of essential medicines? .

There is a dearth of information regarding the prescription pattern in emergency psychiatry service locally despite the availability of plethora of relatively newer psychotropics medications especially atypical antipsychotics that may be useful in the emergency setting. There is also a need to evaluate the use of medicines for pharmacological restraints in keeping with the national Essential Medicine List. Hence, this study was carried out to document the prescription pattern of psychotropic agents used in Psychiatric Emergency Services of the
University of Benin Teaching Hospital (UBTH), Benin City.

\section{METHODOLOGY}

This retrospective study was carried out to involve cases that were admitted through the Accident and Emergency (A \& E) Unit of the UBTH, Benin City, Edo State, Nigeria. The A \& E Unit provides Emergency Psychiatric Services. The UBTH is a tertiary health care facility.

Hospital charts of all mentally-ill patients who were admitted via the emergency unit presenting with emergencies from December 2008 to January 2018 were sought for as much as possible and retrieved. The records that could be obtained included one hundred and fourteen psychiatric patients who presented with pure psychiatric emergencies within the study period. Pure psychiatric emergencies are mental health cases which were judged to require urgent attention and had no comorbid medical or surgical problems. Data on patients' bio-data, diagnosis and psychotropic medications prescribed were extracted from the case notes and documented in a prescription auditing proforma. The medications used were compared with medicines in the National Essential Medicine List (NEML) $6^{\text {th }}$ edition to determine adherence to the National Essential Medicine List.

Data was then entered into IBM SPSS version 21 for analysis. Results were presented in frequencies and proportions and represented in tables

\section{RESULTS}

\section{Biodata}

A total of one hundred and fourteen patients' records were recruited for this study. Males were 60 (57.6\%) while females were $54(47.6 \%)$; with a Male to female ratio of 1.1: 1 . The age ranged from 19 to 98 years. The median and modal ages were 34 and 36.9 years respectively. A total of 72 (63.2\%), 36 (31.6\%), $2(1.8 \%)$ and $4(3.5 \%)$ people were single, married, widowed and separated respectively. 


\section{Oral Psychotropics}

Antipsychotics accounted for 77 (67.5\%) of all prescriptions. Prescriptions were seen for antidepressants 14 (12.3\%), anxiolytics $6(5.2 \%)$ and mood stabilizers 14 (12.3\%). Commonest antipsychotics prescribed were Chlorpromazine 26 (22.8\%), followed by Haloperidol 21 (18.4\%). Others are shown in Table 1. Mood stabilizers commonly prescribed were Sodium Valproate 9 (7.9\%) and Carbamazepine 5 (4.4\%). The commonly prescribed antidepressant was Amitriptylline 8 $(7.0 \%)$ (Table 1). It was noticed that $82(79.9 \%)$ were placed on combination of oral psychotropics while 32 $(32.3 \%)$ were on single medication. However, all 114 $(100 \%)$ of patients had at least one form of oral psychotropic agent prescribed.

\section{Parenteral Psychotropics}

Parenteral psychotropics were prescribed in 86 (75.4\%) of the patients. Parenteral psychotropics were used as combination in $69(69.5 \%)$ than as single medication in $16(14.0 \%)$, The commonest combination of parenteral psychotropic was a combination of Chlorpromazine and Diazepam in 47 $(55.7 \%)$ of cases on parenteral medications. In other cases, parenteral Chlorpromazine and Diazepam were either used alone in $3(3.5 \%)$ each, or combined singly with other parenteral long-acting psychotropics. Prescription of long-acting psychotropics like Fluphenazine Decanoate was seen in $20.8 \%$ and Flupenthixol Decanoate in $17.4 \%$ (Table 2).

Table 1: Oral Psychotropic Usage

\begin{tabular}{llll}
\hline Psychotropic Drugs & EML Present & Frequency & Percentage (\%) \\
\hline${ }^{1}$ Chlorpromazine & Yes & 26 & 22.8 \\
${ }^{1}$ Haloperidol & Yes & 21 & 18.4 \\
${ }^{1}$ Risperidone & Yes & 16 & 14.0 \\
${ }^{1}$ Olanzapine & No & 11 & 9.6 \\
35odium Valproate & Yes & 9 & 7.9 \\
${ }^{2}$ Amitriptylline & Yes & 8 & 7.0 \\
${ }^{3}$ Carbamazepine & Yes & 5 & 4.4 \\
${ }^{4}$ Lorazepam & No & 3 & 2.6 \\
${ }^{4}$ Diazepam & Yes & 3 & 2.6 \\
${ }^{2}$ Fluoxetine & Yes & 2 & 1.8 \\
${ }^{2}$ Sertraline & No & 3 & 2.6 \\
${ }^{\mathbf{1}}$ Thioridazine & No & 2 & 1.8 \\
${ }^{1}$ Clozapine & No & 1 & 0.9 \\
${ }^{5}$ Cognitol & No & 1 & 0.9 \\
${ }^{2}$ Escitalopram & No & 1 & 0.9 \\
${ }^{5}$ Thiamine & Yes & 1 & 0.9 \\
Total & & $\mathbf{1 1 4}$ & $\mathbf{1 0 0 . 0}$ \\
\hline
\end{tabular}

Key $={ }^{1}$ Antipsychotics ${ }^{2}$ Antidepressants ${ }^{3}$ Mood Stabilizers. ${ }^{4}$ Anxiolytics ${ }^{5}$ Memory Enhancer

$E M L=$ Essential Medicine List

Table 2: Parenteral Psychotropic Usage

\begin{tabular}{lll}
\hline Parenteral Psychotropics & Frequency & Percentage (\%) \\
\hline Flupenthixol only.(Not in EML) & 5 & 5.8 \\
Chlorpromazine only.(EML) & 3 & 3.5 \\
Diazepam only. (EML) & 3 & 3.5 \\
Fluphenazine only. (EML) & 6 & 7.0 \\
Chlorpromazine + Diazepam & 47 & 55.7 \\
Flupenthixol + Chlorpromazine + Diazepam & 9 & 10.5 \\
Chlorpromazine + Diazepam + Fluphenazine. & 8 & 9.3 \\
Chlorpromazine + Fluphenazine. & 2 & 3.4 \\
Diazepam + Flupenthixol. & 1 & 1.1 \\
Diazepam + Fluphenazine. & 1 & 1.1 \\
Total & $\mathbf{8 6}$ & $\mathbf{1 0 0 . 0}$ \\
\hline
\end{tabular}

EML $=$ Essential Medicine List 
Table 3: Spectrum of Diagnoses of Psychiatric Emergency Cases

\begin{tabular}{lll}
\hline Mental Disorders. & Frequency & Percentage (\%) \\
\hline Schizophrenia. & 44 & 38.6 \\
Bipolar Affective Disorder-Manic Phase. & 23 & 20.2 \\
Mental and Behavioural Disorder due to & 8 & 7.0 \\
Cannabis in Psychotic State. & & \\
Mania. & 8 & 7.0 \\
Acute Psychotic Disorder & 5 & 4.4 \\
Psychotic Disorder Not Otherwise Specified & 3 & 2.6 \\
Schizoaffective Disorder & 2 & 1.8 \\
Organic Psychotic Disorder & 1 & 0.9 \\
Depression. & 13 & 11.4 \\
Mental and Behavioural Disorder due to & 3 & 2.6 \\
Alcohol in Intoxication. & & \\
Dementia. & 1 & 0.9 \\
Delirium & 1 & 0.9 \\
Mental Retardation. & 1 & 0.9 \\
Panic Disorder & 1 & 0.9 \\
\hline Total & $\mathbf{1 1 4}$ & $\mathbf{1 0 0 . 0}$ \\
\hline
\end{tabular}

\section{Spectrum of Diagnoses}

Psychotic disorders were the diagnoses in 94 (82.5\%) of cases. This included Schizophrenic Spectrum Disorders (SSD) in $44(38.6 \%)$ of patients. Other psychotic disorders were Bipolar Affective Disorder (BAD) in the Manic phase 23 (20.2\%), Mental and Behavioural Disorders due to Cannabis use in a psychotic state $8(7.0 \%)$, Mania 8(7.0\%), Acute Psychotic Disorder 5 (4.4\%) and others in Table III. The non-psychotic disorders documented were depression 13 (11.4\%), Mental and Behavioural Disorder due to Alcohol Intoxication 3 (2.6\%), Dementia 1 (0.9\%), Delirium $1(0.9 \%)$ Mental Retardation $1(0.9 \%)$ and panic disorder $1(0.9 \%)$; all accounting for $20(17.5 \%)$ of the cases.

\section{DISCUSSION}

Drug prescription pattern is important as it helps to understand the pattern by which clinicians in a locale prescribe medications. The findings of psychotropic prescription usage in the psychiatric emergency service of UBTH showed that all patients had at least one form of oral psychotropic agent prescribed either singly or in combination with parenteral psychotropics. Parenteral psychotropics on the other hand were prescribed in over seventy percent of cases. Among the oral psychotropics, antipsychotics were the most commonly prescribed in over two thirds of cases. This finding is expected, bearing in mind that the majority of the patients with mental disorders in Nigeria have been documented to have psychotic disorders. ${ }^{8}$ Similarly, this study found that over $80 \%$ of patients admitted for psychiatric emergencies had psychotic disorders. Antipsychotics are definitely required to manage psychotic disorders along with other modalities of treatment. ${ }^{9}$ Thus, those who were not given oral antipsychotics are likely to have been placed on parenteral antipsychotics. Oral antipsychotics are often preferred to the parenteral ones because they are often cheaper and more readily available than their parenteral forms. Furthermore, their onset of action as well as their side effects are more likely to be gradual compared to the parenteral forms that may in addition to having some immediate effects (which may be desirable sometimes), their side effects are more likely to be rapid and more difficult to tolerate compared to the oral ones. The oral route where feasible, is advisable because it reduces the risk associated with injectables such as abscess formation as well as nerve paralysis especially in young and restless patients. In cases of overdose, oral drug may be prevented from absorption if discovered on time. ${ }^{10}$

It was observed in this study that among the oral antipsychotics, the typical ones such as Chlorpromazine and Haloperidol were more prescribed compared to the atypical ones such as Olanzapine and Risperidone. This is due to the fact that the typical antipsychotics are generally readily available and cheaper than the atypical ones. Furthermore, the majority of the patients pay out of pocket for their medication and may find it easier to sustain the purchase of the cheaper typical antipsychotics compared to the atypicals. Clinicians are usually guided in their prescription pattern by the 
sustained affordability as well as efficacy of medication among the available options. Mental disorder has a tendency to make the patients slide down in their financial status particularly if the support from family is not adequate, (the so-called social drift hypothesis). ${ }^{11}$ Hence, affordability guides the choice of antipsychotic prescription. The type of antipsychotics prescribed is also dependent on the side effect profile of available drugs. Pattern of prescription documented in two psychiatric hospitals in Accra, Ghana by Ashong et al. ${ }^{12}$ found that atypical antipsychotic agent (Olanzapine) was the commonly prescribed antipsychotics. This they alluded to the fact that Olanzapine is less likely to cause extrapyramidal side effects as compared with the typical antipsychotics such as Chlorpromazine and Haloperidol.

In the current study, amitriptyline which is a tricyclic antidepressant is still commonly prescribed than the other groups of antidepressants put together. This may be due to the fact that it is cheaper than the Selective Serotonin Re-uptake Inhibitors (SSRIs). Also, many clinicians in this locale believe that the outcome of treatment is better with Amitriptylline (especially if sedation is needed in patients) than the SSRIs. ${ }^{13}$

Parenteral medications obviously have a large place in the management of patients in a psychiatric emergency service. ${ }^{14}$ The major indication for the use of parenteral psychotropic is in the pharmacological restraint of uncooperative patients. In this study, over $70 \%$ had one form of parenteral medication while only $20.2 \%$ of the cases did not get prescription for parenteral psychotropics. The commonest pattern of prescription of parenteral psychotropics was a combination of Chlorpromazine and Diazepam used to calm down aggressive patients. At the UBTH, this combination has been the pattern for a long time. The combination is often given repeatedly to an aggressive patient but not more than three times in a 24 hour-period to prevent over-sedation and respiratory depression. Acute dystonic reaction may also result from cumulative effect of the drugs (particularly chlorpromazine) if given more than thrice a day. Most commonly used long-acting parenteral medication were Fluphenazine Decanoate and Flupenthixol Decanoate at about the same rate. These two were also more commonly prescribed than other long acting psychotropics because of their relatively lower cost. The long acting antipsychotics have been observed to improve compliance with medications and thus helpful in preventing relapse of psychotic disorders, particularly schizophrenia. ${ }^{15,16}$ However, a few other workers think otherwise. ${ }^{17,18}$ Combination of parenteral psychotropics was more prevalent than single parenteral psychotropic use. Although a single agent of oral or parenteral medication is commonly advocated; but, in the setting of an Emergency Psychiatric Service, the tendency to combine medications is higher. Combination affords the clinician the advantage of using drugs from the various classes so as to achieve the desired effect of calming the patient down and achieving other therapeutic goals.

It is important to note that Schizophrenic Spectrum Disorder was the commonest psychiatric condition presenting to the Emergency Psychiatric Service of the UBTH. This is similar to the pattern documented in another study in this center ${ }^{19}$, but different from the findings in other settings. ${ }^{20,21}$ Of the non-psychotic disorders, depression was the commonest disorder found among patients presenting with emergencies. This pattern of psychiatric presentation sets the pace for prescription pattern seen in this study as most prescriptions were antipsychotics compared to other classes of medications. Ashong et $\mathrm{al}^{12}$ also found that antipsychotics were the commonest psychotropic agents prescribed in two Psychiatric Hospitals in Accra, Ghana.

\section{CONCLUSION}

This study concluded that oral antipsychotics were more prescribed; with Chlorpromazine and Haloperidol being the most prescribed antipsychotics while Amitriptylline was the most commonly prescribed antidepressants at the Accident and Emergency Unit of the University of Benin Teaching Hospital, Benin City. Psychotic disorders were the commonest disorders necessitating presentation in the Psychiatric Emergency Service hence, the accompanied prescription of antipsychotics. Prescription of parenteral psychotropics is quite high with Chlorpromazine and Diazepam on top of the list. Long acting antipsychotics, Fluphenazine Decanoate and Flupenthixol Decanoate were also commonly used in relatively equal frequencies. 


\section{REFERENCES}

1. Nikolas R. Historical changes in mental health practice. In: Thornicroft G, Szmukler G, Mueser KT, Drake RE eds. Oxford Textbook of Community Mental Health. Oxford University Press. 2011. DOI: $10.1093 / \mathrm{med} / 9780199565498.003 .0012$

2. Grob GN. Mental health policy in modern America. In: Thornicroft G, Szmukler G, Mueser KT, Drake RE eds. Oxford Textbook of Community Mental Health. Oxford University Press. 2011. DOI: 10.1093/med $/ 9780199565498.003 .0014$

3. Thomas B, Markus K. Psychiatric outpatient clinics. In: Thornicroft G, Szmukler G, Mueser KT, Drake RE eds. Oxford Textbook of Community Mental Health. Oxford University Press. 2011. DOI:10.1093/med/9780199565498.003.0086.

4. Medical Definition of Psychotropic Medication; Available at: https://www.medicinenet.com/script/ main/art.asp?articlekey $=30808$. Last Accessed on 16/04/2020.

5. Jaramillo-Gonzalez LE, Sanchez-Pedraza R, Herazo MI. The frequency of re-hospitalization and associated factors in Colombian psychiatric patients: a cohort study. BMC Psychiatry. 2014; 14: 161.

6. Tranquilizer. Encyclopedia Britannica. Available at: https://www.britannica.com/science/tranquilizer. Last Accessed on 02-05-2020

7. Jain H, Upadhyaya P, Goyal J, Kumar A, Jain P, Seth V, Moghe VV. A systematic review of prescription pattern monitoring studies and their effectiveness in promoting rational use of medicines; Perspect Clin Res. 2015; 6: 86-90

8. WHO-AIMS Report on Mental Health System in Nigeria. Available at: https://www.mindbank.info/ item/1303. Last accessed 15/04/2020

9. Mental Health Medications. Available at: https://www.nimh.nih.gov/health/topics/mentalhealth-medications/index.shtml . Last Accessed on 10-04-2020

10. Drug Overdose from eMedicine Health. Available at: https://www.emedicinehealth.com/ drug_ overdose/symptom.htm. Last Accessed on 16/04/2020.

11. Hurst C. Social Inequality: Forms, Causes, and Consequences (6th ed.). Boston: Pearson
Education.The British Journal of Psychiatry; 2007; ISBN 978-0-205-48436-2

12. Ashong S, Kretchy IA, Afrane B, Aikins AD. Patterns of Prescription of Psychotropic Medications and Their Adherence among Patients with Schizophrenia in Two Psychiatric Hospitals in Accra, Ghana: A Cross-Sectional Survey. Psychiatry Journal; 2018; 1 10. https://doi.org/10.1155/2018/9850594.

13. Barbui $\underline{\mathrm{C}}$ and Hotopf $\underline{\mathrm{M}}$. Amitriptyline; the rest: still the leading antidepressant after 40 years of randomised controlled trials. Br J Psychiatry. 2001; 178: 129-144.

14. Haw C, Stubbs J, Gibbon S. A survey of the use of emergency parenteral medication at a secure psychiatric hospital. Journal of Psychiatric Intensive. $2012 ; 9 ; 2: 1-8$

15. Kane JM and Garcia-Ribera C. Clinical guideline recommendations for antipsychotic long-acting injections. Br J Psychiatry. 2009; 195: 63-67.

16. Stip E, Abdel-Baki A, Bloom D, Grignon S, Roy MA. An expert opinion from the Association des médecins psychiatres du Québec. Canadian Journal of Psychiatry. 2011; 56:367-376.

17. Rosenheck RA, Krystal JH, Lew R. Long-acting risperidone and oral antipsychotics in unstable schizophrenia. New England Journal of Medicine. 2011;364: 842-851.

18. Adams CE, Fenton MKP, Quraishi S, David AS. Systematic meta-review of depot antipsychotic drugs for people with schizophrenia. Br J Psychiatry. 2001; 179:290-299.

19. Aina IO, Otakpor AN. Pattern of adult psychiatric emergency cases presenting at a University Teaching Hospital in Nigeria. Annals of Biomedical Sciences. 2017; 16; 1. Available at: https://www.ajol.info/ index.php/abs/article/view/154452 Last Accessed 09-09-20202

20. Shakya DR, Shyangwa PM, Shakya R. Psychiatric Emergencies in a Tertiary Care Hospital. Journal of the Nepal Medical Association. 2008; 47: 28-33.

21. Mahgoub_OM. Psychiatric Emergencies at a University Teaching Hospital In Eastern Saudi Arabia. J Family Community Med. 2000; 7: 53-59. 